\title{
Research on Reform Directions of Physical Education in Universities from Sunshine Sports Perspective
}

\author{
HaoqinLi \\ Zhengzhou University of Industrial Technology, Zhengzhou, 451150, \\ China
}

\begin{abstract}
Physical education is an indispensable part in the curriculum system in universities. It has a crucial influence on students' growth and employment. However, the vague teaching objectives, backward teaching model and unscientific teaching assessment of the traditional physical education cannot stimulate students' interest and even hinder the growth of students. Based on the concept of sunshine sports, universities must clear teaching objectives, strengthen content construction and improve teaching evaluation to enhance the quality of physical education.
\end{abstract}

Keywords:sunshine sports, physical education, reform directions

\section{Introduction}

At present, the physical quality of university students is not very ideal. The health problems of young people get widespread attention in the community, in order to effectively improve the physical fitness of young people is not ideal, China launched the "sunshine sports teaching activities, to increase the pace of reform in sports teaching in universities, effectively solve the physical quality of college students is not high. It can meet the needs of college sports teaching, and guide students to actively participate in physical exercise. The sunshine sports, in fact, adheres to the "health first" ideology and aims to improve the overall physical quality, training students good sports habits. Sunshine sports can promote college students love sports, develop positive sports behaviour. Sunshine Sports urge students to leave the classroom, close to nature, appreciate the joy of sports, so 
that students grow up in a healthy and happy atmosphere. It can improve the physical quality of students. In the process of practical work in universities need to pay attention to the cultivation of students' physical quality, carry out a variety of sports activities to encourage students to actively participate in sports courses, improve college physical education system, promote the college sports curriculum diversification and integration. In short, colleges and universities in the physical education process, we need to adhere to the "people-oriented" work philosophy, respect for student personality development, and create a good campus sports teaching atmosphere. Our goal is to improve students' physical exercise enthusiasm and the physical quality of university students.

\section{Existing problems of physical education in universities}

\subsection{Fuzzy goal of physical education}

Today, the target consciousness of many universities is relatively weak. In the new situation, college students should not only master professional knowledge and professional skills, but also need to have good physical and psychological quality, in order to better adapt to the rapid development of society. University must also recognize the importance of students' physical quality training to enhance the awareness of students' physical quality training. However, due to the impact of traditional teaching, the lack of perfect sports teaching system of many universities, many college students have not really formed a good habit, if not supervised by teachers, it is difficult to consciously participate in physical exercise and physical fitness of students will be decreased. Nowadays, the social competition is becoming fiercer. If the college students want to survive and develop in the fierce social competition, they must improve their physical quality. University is the cradle of cultivating talents of higher education in our country, and also an important stage for the establishment of lifelong sports concept. Students' physical and mental health is in the critical period development. Some teachers said that physical education is to let students play, relieve the tension of the burden. Some teachers believe that physical education is not so strict, students can pass the exam. Although the Ministry of education put forward clear goal requirements for public physical education, but affected by the concept of adverse physical education curriculum, the goal of physical education is not clear.

\subsection{Backward model of physical education}

Many physical education teachers are still using the traditional sports teaching way. The teaching methods are single, and not the teachers in class teaching and students' extracurricular exercise together, resulting in many students are not aware of the importance of physical exercise. In the traditional sports teaching mode, teachers are teaching, students' passive learning, teachers classroom occupies most of the time, the practice time is very small, the students can really master the sports skills. Despite many curriculum reform, the course content is still boys dominated by basketball, girls to aerobics based, formed to emphasize 
the basic technical skills of physical education teaching pattern. The boring curriculum content directly led to the lack of interest in physical education students and enthusiasm, for the sake of credit and barely copes. In addition, due to the decline in the overall physical fitness of young people, some students can not complete or achieve the existing standards of assessment of teaching content. Existing teaching materials generally follow the old patterns and content, more complex technology, did not take into account the physical and physical condition of college students decline, teachers cannot fully refer to the content of teaching materials. The creation of teaching materials is lack of innovative consciousness, not only ignore the latest achievements of the development of sports science, but also fail to follow the sunshine sports teaching objectives and social development needs.

\subsection{Unreasonable assessment of physical education}

The teachers' performance evaluation of physical education is generally given priority to the research results, supplemented by teaching results. Admittedly, the scientific research achievement has the quantification characteristic, relatively is the fair appraisal method and the method. However, the theoretical knowledge of physical education teachers is weak; the level of scientific research is not high. There is no advantage in scientific research. More from the perspective of scientific research physical education teachers overall ability and level often lead to some teachers no teaching. Some teachers think, teaching ability again strong, teaching level again high, also cannot be named professor. As long as teachers can complete the teaching tasks according to the regulations, no need to work hard. In the teacher evaluation, the evaluation system is to strengthen the number of papers published, weight and other indicators of project level of PE teachers, and ignore the sports teaching to improve students' physical quality as the goal, is not conducive to play the guiding role of the evaluation system of PE teachers. Physical education teaching evaluation of the significance lies in the discovery of advanced and backward, and by encouraging the advanced method and spur the backward driven sports teaching quality and students' physical qualities, however many college physical education teaching evaluation work only at the formal level, according to the evaluation results lack of information feedback, reward and punishment and other supporting work mechanism. Substantial cause of physical education teaching evaluation work is difficult to achieve.

\section{Reform countermeasures of physical education in universities based on Sunshine Sports}

\subsection{Clear teaching goals}

Reforming the traditional concept of physical education and making clear the goal of teaching is the urgent matter of public physical education reform. The reform of undesirable educational ideas needs the joint efforts of society, family and school. Through the publicity posters, school board and windows and other 
multi-channel and multi way vigorously promote sun sports to enhance the students ideological recognition of sunshine sports. At the same time, arouse the historical responsibility of public physical education teachers, to make them aware of the importance of the work of physical education and the urgency of the specification of the left or the right concept of physical education, a profound understanding of the purpose and meaning of the sun sports, so as to establish a clear and specific teaching objectives. Sunshine sports education aims to realize and improve the students' physical quality target through the variety of sports participation, and in accordance with the provisions of guidelines for grain national ordinary college sports curriculum teaching of sports curriculum in universities. The aim of education is to enhance the physical fitness of students and improve students' physical quality. Therefore, the sunshine sports education goal and education goal is consistent, namely through the implementation of sunshine sports is helpful for higher education to enhance the physical fitness of students and improve students' physical quality target, and achieve the goal of higher education is helpful to further enrich the connotation and denotation of sunshine sports education. Two partsmutually interact and collaboratively develop.

\subsection{Strengthen content construction}

Teachers need to be aware of the importance of improving students' physical exercise consciousness, advocate students' hobbies to choose courses and teaching teachers according to personal interests, departments of the university educational administration management work according to the teaching arrangements to publish relevant content in advance, students can learn to understand and study content in the degree of difficulty to choose more in line with their own ability and personal interests of the movement. In the sports teaching process, but also need to create entertainment teaching content, students in the class, not only needs to consider the factors of personal employment and personal hobbies, can also be combined with classroom learning and leisure. The economic and social development has spurred the concept of life changing, survival activities and outdoor sports has become an important part in people's life, through the combination of classroom teaching and living activities to enhance the attractiveness of students can accept the teaching content, cultivate students to be creative, to guide students to form a healthy lifestyle. Teachers can select some games, combine the teaching content and the game, creating a good classroom atmosphere and cultivate students' team spirit. China has different regions have different cultural forms. Universities can make full use of the cultural resources of various regions, and innovate on the basis of traditional sports, so that students realize the importance of sports.

\subsection{Improve evaluation system}

The evaluation system establishment of physical education is an important guarantee mechanism for long-term development of sunshine sports. It is helpful for teachers to devote themselves to sunshine sports teaching. The teacher is the 
sunshine sports education practice, design education mode, teaching program and the implementation of the main body, it is necessary to carry out the sunshine sports teacher innovative teaching construction and evaluation mechanism to ensure the effective implementation of the sunshine sports education. We incorporate the innovative teaching consciousness, theoretical level, teaching ability, professional moral level and educational performance into the teacher evaluation system. We further refine it into an operational, quantifiable evaluation index system. According to the evaluation results of the evaluation system, we form a reasonable evaluation of teachers' innovative teaching of sunshine sports. The establishment of the teachers rank evaluation results of the system promotion and salary reward incentive management system based on the evaluation results and physical education teachers' personal interests closely. The establishment of a unified compensation mechanism ensures the long-term unremitting, unswervingly promoting the development of sunshine sports.

\section{Conclusion}

With the deepening and development of university education reform, the government put forward the concept of sunshine sports. In the course of its implementation, we clearly recognize the problems in university physical education. Under the background of sunshine sports, we should clear teaching objectives, strengthen content construction and improve the evaluation system. We will promote and perfect the university sports teaching work through the contiguous teaching practice.

\section{References}

[1]Wang Man, On Systematic Innovation of the Sunlight High School Sport Education, Journal of Southwest China Normal University (Natural Science Edition), 39(9), pp. 185-188,2014.

[2]Jin Anming, Yang Rui, Wang Qi, Wang Hao, Lv Chunshuang, Research on the Universities Public P. E. Course Reform in Sight of "Sunshine Sports", Journal of Harbin Sport University, 32(5), pp. 61-64, 2014.

[3]Sun Jianwei, Mi Jie, Research on the Operation Mechanism of "Sunshine Sports" Serving College Students in Ordinary Colleges, Value Engineering, 35(6), pp. 61-64, 2016.

[4]Zhang Enli, Restriction and Countermeasures of University Sun-shine Sports Long-effect Development in China, Journal of Nanjing Sport Institute(Natural Science), 14(6), pp. 1-4, 2015. 